\section{Briginal anrticleg.}

\section{THE PARASITIC ORIGIN OF CANCER.}

HY J. COLLINB WARREN, M.D.

THe achievements of bacteriology have not only aroused the hope that diseases hitherto considered incurable may come within the grasp of modern therapeutics, but have also emphasized the fact of our complete powerlessness in the presence of cancer, except with the uncertain aid which the knife has given us.

'The etiology of cancer still remains an unsolved riddle. Any work in this domain of pathology deserves, therefore, all the encouragement which a sympathetic professional public can give, as it is but the preliminary step in a direction towards which many eyes are straining, and which may point the way to that goal which the surgeon has hitherto sought for in vain.

The following notes, cullected for the purpose of instruction to a medical class, are presented as some of the most recent contributions to this question, and are, perhaps, of sufficient novelty to interest the members of this Society. It would, of course, be futile to draw any well-defined conclusions as yet from the work that has been done.

\section{BACTERIA IN CANCER.}

Scheuerlen reported in 1887 a cancer bacillus, which he had obtained from cultures of ascites and hydrocele fiuids, inoculated with material taken from cancer of the breast. On the third day a colorless film was seen on the surface of the serum, which changed to a yellowish brown color. Under the microscupe the culture was found to be composed of short bacilli, two micro. millimetres long and four-tenths of a micromillimetre wide, with spores, which could readily be stained with the ordinary reagents. They could not be found in colored section, but were obtained from the cancer juice. Inoculation of bitches by injecting material from the pure culture into the posterior breast gland, produced at the end of fourteen days, a circumscribed tumor the size of a walnut. In the animals, killed four weeks after the inoculation, the tumors were found to be composed of epithelial cells, in which the spores of the bacilli could be seen. Francke, at the same time (1887) made similar investigations with sarcomata, and obtained a bacillus of sarcoma. He also obtained the cancer bacillus from carcinomatous growths. The surcowa bacillus measured three to four micromillimetres in length and four-tenths of a micromillimetre in width. He obtained cultures, but inoculations failed to produce malignant growths. These observations have not been coufirmed by subsequent observers; and Senn, Baumgarten, and others, are not disposed to accept them as the micro-organisms of malignant disease.

\section{PROTOZOA IN CANCER.}

The many striking little bodies which have so long been recognized as characteristic of epithelial cancer under the name of epithelial nests - globes epidermiques - have recently been studied with renewed interest. 'The glistening bodies which form the centres of these masses, around which the epithelial cells appear to be arranged concentrically, were supposed by some to be epithelial cells in a state of

1 Rem before tlio Boston Socioty for Medioal Improvement, November 24,1890 . colloid degeneration or cells having undergone the horny change. Virchow, however, as early as 1861 did not accept this view, but named them physalides, ( $\phi v \sigma \eta \eta, \iota \sigma, a$ bladder), or broad cavities; and this idea of an endogenous cell formation was adopted also by Butlin in his description of Paget's disease of the nipple. Within the last few years the view has been gaining ground that, these cells existing within the epithelial cells did not belong to the human organism, but were animal parasites of a very simple organization, cousisting only of a single cell, and properly classified as one of the very numerous forms of protozoa.

'The sporozoa, to which grand division of the subkingdom of the protozoa, the organisms in question belong, are described by Balbiani, ${ }^{2}$ as being composed of five different species of organisms, namely : The gregarineum, the coccidium, the sarcosporidium, the my xosporidium and the microsporidium.

The sporozoa are parasites that are widely dis. tributed. We find then in all animals, from man down to the infusoria. Some of them give rise to epidemics of a grave character in animals, as the coccidium in the rabbit - quite a common disease in France but rarely seen in this country. The sarcosporodium gives rise to an epizootic in sheep and poul. try. A number of fish die annually of disease pro. duced by the presence of the myxosporidium. And the organism which has caused such ravages among the silk-worms of France, producing the maladio de la pébrine, is the microsporidium.

'The gregarinidia are elongated cells, showing a tendency to sub-division by the presence of constrictions. They each have a single nucleus. When sporulation takes place two cells enter into conjugation and form a single cyst with a wall of double contour, in which are formed the spores which are each enclosed in a diatomelike capsule. 'They were for this reason called the pseudo-navicella. When the condition favorable for the segmentation of the spores occur, two or more sickle-shaped cells form in them. 'These cells have amoboid movements, and entering a new cell remain there until they become a fully developed cell, at which period their life becomes an extra-cellular one.

The coccidia, which interest us especially, owing to their presence in epithelial cancers, are somewhat similiar in their structure to the gregarisidia. They differ waterially from the latter organisms by the prolonged intercellular life. The organism consists of finely granular masses of protoplasm, with a nucleus not easily seen, and without an enveloping membrane during its period of growth. During this period it lives in an epithelial cell, where it finally becomes encysted. Before the protoplasm of the organism becomes segmented and sporulation takes place, it breaks away from the epithelial cell, and may be voided from the intestine of the infected animal. After sporulation occurs, it may again be taken into the digestive tract of another animal, somewhat after the manner of more complex animal parasites.

The coccidia are divided into several sul-varieties, according to the method of spore formation.

Steinhaus describes the changes of the coccidium in the intestinal tract of the salamander, which, however, differ's in certain important particulars from that of Balbiani. The different stages of the peculiar sickleshaped cell-formation are very beautifully illustrated. ${ }^{8}$ - Legnns our les Sporozaires, Paris, 1884. Modico-Chlrurgical Transautions, 1887.

"Virchow's Archiv., Band 115, Hoft 1, v. 176. 
The cells he describes have nuclei and nucleoli; they entered the nucleus of an intestinal epithelial cell; sometimes there are one or more such cells in the nu. cleus. The nuclei of the parasites presently begin to divide and sub-divide until a necklace of nuclei may be seen in the interior of the organism now grown so large as to have distended und ruptured the epithelial nucleus which contained it. The next change is the formation around these nuclei of the sickle-shaped cells which are disposed around the surface of the organism like the meridians of a globe. Later, these cehls become detached from one another, change their shape, and when ready for release appear as amcboid corpuscles ready to invade a now cell. Steinhaus saw no enveloping membrane, and the changes abovo described ull occurred inside the epithelial tract. One of the best known forms is the coccidium oviforme, which is found in the intestine and liver of the rabbit, where it forms cuseous nodules. Here the cyst formation is wellmarked, and occurs within the epithelial cells, whose nucleus is pushed to one side. 'The further development of the cyst contents is extra-cellular in this case. Bulbiani has been able to cultivate them in water and wet sand and thus observe the changes which take place during sporulation.

Cases of casseous tumors in man have been described by Gübler, in which these organisms have been found; and Podwyssozki has described, as karyophagus hominis, organisms which attack the nuclei of the liver cells and after ovulation and sporulation destroy the liver cells, and lead to irritation of the connective tissue stroma, giving rise to icterus and cirrhosis."

The sarcosporidia are generally found in the mus. cular tissue of vertebrates. They are also called by Balbiani, Les Psorospermies utriculiformes. 'These long tubes form at the expense of the muscular fibre. They are seen in pork easily, with a power of forty diamotres. Finally, spores form partly in globular masses and partly singly. The cells which form vary in shape.

The myxosporidia are found in the skin and mucous inembrane of fishes. The spores present a much greater variety of forms and more complex structure. They are provided with projectile threads.

The microsporidia are so called by Balbiani on account of the extremely smull size of their spores, which are not more than four micromillimetres by two micromillimetres. They have been occasionally mistaken for bacteria. They possess a sac with a double contour, which can readily be distinguished when it ruptures at one end, and allows its contents to escape. These appear as amoboid bodies which penetrate the epithelial cells, muscular tissne and other structures of the silkworm and develope into sarcodic masses, in which sporulation takes place. The parasite peuetrates into the reproductive, and other organs, and does not confine itself to the epithelial cells.

That the pathogenic qualities of the sporozoa, or the psorosperms, as the French authors call them, were not entirely confined to animals, has been recoguized for many years. One of the earliest communications by Gübler, in 1868, upon the growth of these organisms in man, has already been referred to. It has been thought possible that the growth described by this author was a cylinder-cell cancer of the liver in a stage of retrograde metamorphosis. Coccidia have also been found in the intestiual caual of man, in

- The I'athogenic Sporozoa. Ramsay Wright. T'uronto, 18.0. pleuritic effusion, and in the interstitial tissue of the kidney in a case of Bright's disease.

The contagious nature of molluscum contagiosum was proved by Retzius in 1870 , by inoculation experiments; but Neisser, in 1888, first showed that the "molluscum corpuscles" supposed to be the result of a degenerative process, were really parasitic. $\mathrm{He}$ succeeded in tracing them through their different stages of development and in identifying them with the coccidia. According to him, these corpuscles consist of epidermic cells containing the remains of nuclei and filled with spores, and that the disease itself is due to the invasion of the cells of the rete mucosum by these parasites. The glandular appearance which has always hitherto suggested the sebaceous origin of these tumors, is now recognized as due to a papillary growth of the malpighian layer of the skin. The name epithelioma contagiosum has been suggested as a more appropriate name for the affection. A contagious skin disease in poultry originally described by Bollinger in 1873, as seated in the epidermic layer of the skin, is shown by Pfeiffer to be due to the invasion of the coccidium. The disease may be artificially pro. duced by inoculating the spores; but if planted in the mucous membrane of the throat instead, it will produce a diphtheritic inflammation which is very contagious. In this case the spores assume a flagellate instead of amceboid form. As Wright intimates this polymorphism is of great interest, in view of the remarkable, and as yet only partly understood polymorphism of the malarial parasite.

A rare form of disease of the epithelial layers of the skin in man was described simultaneously by Durier ${ }^{6}$ as psorospermose folliculaire végétante and by J. C. White ${ }^{6}$ as keratosis follicularis. Darier attributes the disease to the presence of organisms resembling the coccidia. According to his description, we find a papillary-like growth of the cells of the rete near the neck of the hair follicle, the sebaceous gland not being affected. Near the neck of the follicle the anatomical arrangement is more like that of the skin. In the malpighian layer at this point he found a number of round bodies with a glistening menbrane of double contour which looked not unlike cartilage cells in their capsule. The enclosing membrane contains a granular protoplasm which nearly fills it, and has a uucleus with nucleoli. On treating a mass of epithelial cells in potash, he found these bodies could be isoluted, or they could be well demonstrated by softening the cells in ammonia and coloring them with hæmatoxylin. In the deeper portion of this epidermal mass these organisms can be seen situated in the interior of epithelial cells. The epithelial cells elsewhere do not appear to have undergone any degeneration to account for the presence of such a body. He concludes that they are probably of parasitic origin. Both Mulassez and Balbiani, by whom the specimeus prepared by Darier were examined, agreed that these bodies were well marked examples of the coccidium. Malassez claims to have recognized since 1876 that the granular and higbly refractive cells seen in epithelial growths and which are sometimes euclosed in a membraue, presented certain analogies to the psorosperms of the rabbit. In two cases observed with Albarran, be was able to demonstrate that the organisms were really coccidia, but he did not feel able to stute definitely 
that the tumors were the cause of the new formation. 'These were demonstrated to the Société de Biologić, in 1889 .

But these organisms are not found in the so-called epithelial cancers alone, that is in cancers of the skin. Thoma ${ }^{7}$ found the coccidia in cancerous growths of various organs, ustally in the nucleus but also in the protoplasm of the cells. 'They were readily shown by eosine and hamatoxylin staining, but his descriptions are incomplete. Paget's disease of the nipple, or as the distinguished author himself called it " Disease of the mammary areola preceding cancer of the mammary gland" has been restudied recently by Wickham $^{\circ}$ who, together with Darier, had fouud the cocidium not only in the preliminary eczema of the nipple, but in the subsequent disease of the gland.

In the earlier stages of the affection the only change to be noted is the presence of certain cellular bodies in the malpighian layer which are clearly not epithelial in nature. 'They are generally considerably larger than the cells of that layer: They take the staining differently, and have a decidedly different grain to their protoplasin, but one of their most striking peculiarities is that they are usually retracted into angular masses, and thus leave irregular clear spaces between themselves and the surrounding epidermic cells, a contraction probably due to alcohol. A certain number of them are enclosed in a hyaline membrane of double contour, and when the alcoholic shrinkuge occurs, the protoplasm of the cells separates from the membranes which remain in contact with the other cells. Some of these bodies are round or oval, and present, with their thick and glistening capsules, a striking appearance. We often see several nuclei, some of which are quite large and irregular in shape.

One of the most characteristic features of these organisms is their seat within the epithelial cells; the nucleus of the contuining cell being pressed aside by the parasite. 'The nuclei of the coccidia are situated sometimes in the centre and sometimes at the edge of the protoplasmic mass. The retruction of the latter gives the organism the appearance of a cell in a stage of degeneration, as has so often been attributed to it hitherto. This retraction gives the affected epidermis its cribriform appearance. When the number of these organisms is stnall they may not be seen at all in many sections. They are, however, easy to find in the scrapings from the cut surface of the diseased epithelium. Their size is about double or treble that of the adjacent cells, but occasionally they may be enormous, their diameters being nearly equal to one-third of the thickness of the rete malpighii. They are to be found in all the layers of the epidermic portion of the skin. They are more numerous near the first row of the cells of the rete; at this point they are rarely encysted but appear usually as a mass of nucleated protoplasm more or less retracted, in the centre of a clear space. Higher, the corpuscles are more frequently encysted and usually larger. In the horny layer they are usually flattened out, and hente are less apparent.

'The parasites become more numerous as the disease progresses, and the intervening epithelial cells are much compressed and distorted in consequence. The structure is now filled with holes, the result of the retraction of the protoplasm of the coccidia. The

7 Uber eigenartige parasitüre organismem in den epithelzellen der carolnome Fortsoliritt d. Med., 1889, No. II.

St. Bartholomew's Huspital Roporti, 1874.

- Malado do Pagot, Parts, 1890. large cells above mentioned are veritable cysts containing a granular material in which are a number of oval corpuscles. The appearance is not unlike that of a miliary abscess except for the enveloping membranes. It appeared to Darier that these cysts rising near the surface of the horny layer in consequence of the epidermic proliferation allowed their contents to escape and to become mingled with the débris which goes to form the scab. Around the cysts we see the cells of the rete very much compressed and arranged concentrically and we generally see at the border of the cyst wall the flattened-out nucleus of the cell which contains it, the remainder of the cell being recognized by a line which more or less completely encloses the cyst wall. It is in this way that the well-known epidermic bulbs are formed. As to the future life of these organisms; some of the cysts appear to be thrown off from the surface in the desquamation and scabbing which occurs; others after rupturing, spread their contents in the surrounding tissues. Some of the larger cysts show a dilatation at one of its peripheral portions which is probably a change preparatory to rupture of the cysts after which the amœboid bodies escape between the cells of the rete and eventually forcing their way into new cells, continue the process of development at the expense of their protoplasm. These corpuscles may also come in contact with an excoriation of the surface and penetrating the epidermis, sturt a new centre of growth. It is possible that the original infection may take place in this way. One of these corpuscles may become implanted between the papilla of the nipple during washing, as we know that the coccidia live in water. Or they may become attached to the orifices of the large sebaceous glands of the scrotum and penetrate the epidermis at some excoriated point.

Wickham tried inoculation in a number of rodents without obtaining any result. He also inoculated him. self by scarifying the epidermis of his right forearm and planting upon the raw surface a pulpy mass of scales suspended in distilled water. A glass crystal was placed over the wound and kept there eight days with a negative result. Cultures of similar masses upon moist sand which had been previously sterilized gave the following results : At the end of sixteen days while the other cells had lost their distinctive characteristics the cysts were perfectly well preserved. Wickham thinks there is no reuson to doubt the true nature of these organisms. It might be supposed that these cells were in the process of vacuolation, but the contraction of the protoplasm takes place around the nucleus and does not push it to one side. 'The readiness with which the protoplasm and nuclei are colored are also arguments ugainst a degenerated structure.

According to Wickham these organisms exert a direct pathogenic action upon the epithelial cells and as the result of the irritation thus produced the cells return sooner or latter to an embryonic state and their future proliferation and active growth appear to be caused exclusively by these organisms, which find in these new epithelial growths an excellent culture soil.

Cornil has seen similar organisms in certain cancers of the uterus and the coccidia have also been observed in cases of rodent ulcer.

In all these forms of epithelial disease the epithelial nests are, as you know, a familiar sight. It becomes a matter of much interest to determine therefore 
whether similar organisms are to be found in other forms of cancer in which the epidermic structures are not found.

Nils Sjöbring's communication upon the presence of a protozoa-like organism in several cases of cancer of the breast examined by him are therefore of special interest at this time. 'The tumor from which most of his preparations were obtained was a typicat cancer of the breast, of the medullary type. It was hardened in alcohol, inbedded in paraffine, and cut with the microtome. Staining was produced by Erhlich's haematoxyline and eosine method, and clenred up in xylobalsam.

What first called his attention to theso organisms was their deep-red staining in contrast to the pink color of the surrounding elements.

In the earliest stages of its grow th the organism in question appears as a small, round, protoplasmic body, about two micromillimetres in diaweter. Several of them are found in each alveolus. One of the peculiarities of this little structure appears to be that, having eutered an epithelial cell, it proceeds to penetrate the nucleus, where it remains during the early stages of its development. Such a habitation of the nucleus is mentioned by Steinhaus in his description of the coccidia of the sulamauder; but none of the French authors mention such action of the organism in the epithelial growths.

These corpuscles are usually first seen near a uucleus, but they may be some little distance off. They are not found in direct contact with the contents of the cell, but are surrounded by a clear zone, as if they were in the middle of a space hollowed out of the interior of the cell. There is no lining membrane to this cavity, the walls of the cyst-like space consisting merely of a somewhat thickened layer of the adjacent protoplasm. This bright border, perhaps due to Bhrinkage of the protoplasn, serves to distinguish them readily from the nuclei of the cell. Huving emigrated from the nucleus they appear now as irregular or flusk-shaped masses of protoplasm still without a nucleus altaining the size of a diameter of fifteen or more micromillimetres. They do not have any welldefined cell wall. The organism enters now into the free stages of its existence, und may be found between the cells of the cancer or in the ducts of the mammary gland. It soon enters the, cancer cells however, apparently to obtain sustenance from their nuclei. We see now large irregular protoplasin.like organisu in the protoplusm of the epithelial cell and separated from it by the bright zone. It may have already attached itself to a nucleus which it soon surrounds and encloses into its own substance so that the nucleus of the cancer cell is now embedded in the protoplasm of the parasite. Changes soon begin now to appear in the protoplasm of the caucer cell ; its peripheral portion becomes pointed and takes staining feebly and finally it disappears altogether, or is pushed aside leaving the parasite in undisturbed possession of its nucleus. The next change is seen in the nucleus itself; it seems to be undergoing a breaking-down and assimilation into the substance of the parasite. The hyaline portions separate and collect in the shape of drops here and there in the neighborhood of a clump of chromatine granules. These drops soon become absorbed and give the protoplasm of the parasite a some. what lighter color; the chromatine granules are either seen protruding from the edges of the cell or entirely free in the neighborhood; they are inplurently discarded; at all events, they disappear entirely. At this time the organism is found to be surrounded by a distinct membrano.

We now enter upon the next period in the development of the parasite, that of sporulation. The first indication of this process is the appearance of a number of dark-red points, which as they enlarge develop into bent rods with club-shaped ends. They are about three micromillimetres in length. As they develop it is seen that they are each enclosed in separate capsules. The organisn finally becomes transformed into a cystlike sack with a membrane which encloses a number of bright egg-slaped bodies, each of which encloses a spore. Eventually the membrane of the cyst is rup. tured, and the spores are set free; and finally the small mass of protoplasm contained within the capsule is allowed to escape through a longitudinal rent on one side of its capsule. The amcboid masses of protoplasm thus set free enter the nuclei of new cancer cells and begin again the cycle of development.

Quite a number of the organism in the first and second stages of its development are found in every alveolus. The fully developed spore cysts are, however, rarely seen.

The organism, it will be seen, has a very destructive influence upon the epithelial cells, and we see in the masses of detritus, when the cancer cells have broken down, a number of organisms which are evidently, from their shape and their coloring power, and other peculiarities, of a parasitic nature.

Sjöbring regards them as similar to that group of the sporozoa known as the microsporidium, or tho organism which is the cause of the silk-worm disease.

The organisms were found by him in six out of the seven cases of cancer examined. In the seventh the inability to stain the nuclei of the cells showed that the specimen had not been properly preserved. The author has also found the microsporidia in a case of primary cancer of the liver, and in a primary cancer of the prostate gland. No culture experiments were made. Attempts have been made for a long time to inoculate cancer into animals or from one animal to another. Hanau succeeded in transmitting typical epithelioma from a rat to two other rats. He also succeeded in trausplanting an epithelioma from one part of a man to another portion of his body, aud in obtaining metastatic deposits around the iwplanted growth. At a recent meeting of the German Surgical Association Wehr showed three dogs, in whose peritoneal cavities cancer had been transplanted from a man; one of the animals died of cancer; the others were still alive, but had a number of nodular masses in the peritoneal cavity.

A recent monograph by $P$ feiffer ${ }^{10}$ describes the relation of the protozoa to certain pathological conditions, more particularly in animals.

"Is the doctor in?" asked a tramp at the door of an Arch Street physician yesterday. A few minutes later an oldish female came to the door. "I jist wanted to see if the doctor wouldn't give me a pair of his old pants," said the tramp. "I'm the doctor," replied the lady. "The tramp had several attacks of vertigo as he dropped down the steps.- Pliladelphia Record.

10 Die Protozon als Krank helts orroger. Juna, 1890. 